8 Dickens G. Mental health outcome measures in the age of recoverybased services. Br J Nurs 2009; 18: 940-3.

9 MacKeith J, Burns S. The Recovery Star: User Guide (Second Edition). Mental Health Providers Forum, 2010.

10 MacKeith J, Burns S. The Recovery Star: Organisation Guide (Second Edition). Mental Health Providers Forum, 2010.

11 Mental Health Providers Forum. Recovery Star Online Analysis - The Growing Picture. Mental Health Providers Forum, 2010.

12 Mental Health Providers Forum. Mental Health Recovery Star Organisational Guide. Mental Health Providers Forum, 2008.

13 Beazley PI. The Recovery Star: is it a valid tool? (letter). Psychiatrist 2011; 35: $196-7$

14 Burgess P, Pirkis J, Coombs T, Rosen A. Assessing the value of existing recovery measures for routine use in Australian mental health services. Aust NZ J Psychiatry 2011; 45: 267-80.

15 Kline P. A Handbook of Test Construction: Introduction to Psychometric Design. Methuen, 1986

16 Anthony WA. Recovery from mental illness: the guiding vision of the mental health service system in the 1990's. Psychiatr Rehabil J 1993; 16 $11-21$.

17 Topor A, Borg M, Di Girolamo S, Davidson L. Not just an individual journey: social aspects of recovery. Int J Soc Psychiatry 2011; 57: 90-9.
18 Vogel-Scibilia SE, McNulty KC, Baxter B, Miller S, Dine M, Frese 3rd FJ. The recovery process utilizing Erikson's stages of human development. Community Ment Health J 2009; 45: 405-14.

19 Corrigan PW, Giffort D, Rashid F, Leary M, Okeke I. Recovery as a psychological construct. Community Ment Health J 1999; 35: 231-9.

20 Coid J, Hickey N, Kahtan N, Zhang T, Yang M. Patients discharged from medium secure forensic psychiatry services: reconvictions and risk factors. Br J Psychiatry 2007; 190: 223-9.

21 Uppal G, McMurran M. Recorded incidents in a high-secure hospital: a descriptive analysis. Crim Behav Ment Health 2009; 19: 265-76.

22 Parkes J. A study of the nature and management of aggressive incidents in a medium secure unit. Med Sci Law 2003: 43: 69-74.

23 Muthukumaraswamy A, Beer M, Ratnajothy K. Aggression patterns and clinical predictors of inpatient aggression in a mental health low secure unit population. J Psychiatr Intensive Care Units 2008; 4: 9-16.

24 Isherwood S, Brooke D. Prevalence and severity of substance misuse among referrals to a local forensic service. J Forens Psychiatry Psychol 2001; 12: 446-54.

25 Gudjonsson GH, Webster G, Green T. The recovery approach to care in psychiatric services: staff attitudes before and after training. Psychiatrist 2010; 34: 326-9.

26 Slade M. Personal Recovery and Mental IIIness: A Guide for Mental Health Professionals (Values-based Medicine): 37. Cambridge University Press, 2009.

\title{
Selecting staff for a personality disorder service: report from the field ${ }^{\star}$
}

Tennyson Lee, ${ }^{1}$ Claire Ellingford, ${ }^{2}$ Samantha Blackburn, ${ }^{1}$ Elizabeth Bishop, ${ }^{1}$ Nikolas Ragiadakos, Patricia Elcock, ${ }^{3}$ Kamaldeep Bhui ${ }^{4,5}$

The Psychiatrist (2012), 36, 50-54, doi: 10.1192/pb.bp.111.034892

${ }^{1}$ DeanCross Tower Hamlets Personality Disorder Service, East London NHS Foundation Trust; ${ }^{2}$ Tower Hamlets User Involvement Project: ${ }^{3}$ Active Images Company; ${ }^{4}$ Centre for Psychiatry, Barts and The London School of Medicine and Dentistry; ${ }^{5}$ Careif

Correspondence to Tennyson Lee (tennyson.lee@eastlondon.nhs.uk)

First received 13 Apr 2011, final revision 1 Aug 2011, accepted 15 Sep 2011
Aims and method To select staff for a personality disorder service by exposing applicants to anticipated challenges. Applicants took part in a role play, an unstructured group with fellow applicants and numbers of the interviewing panel, and a panel interview. A service user representative was involved from the initial planning stage.

Results Multiple assessment methods enabled fine discrimination between applicants. Appointed staff said they felt the interviews were a valid test of required skills and have been well regarded by patients in the programme.

Clinical implications Selecting staff for a personality disorder service benefits from using multiple interview methods. The service user representative and role-play actor can contribute crucially by representing the patient's perspective. Key domains to assess include the applicant's psychological qualities, psychiatric skills and ability to work in a team.

Declaration of interest None.
Selecting the 'right' person for a personality disorder service is difficult. The applicant may have all the credentials on paper, and may even interview very well, but whether they

*This paper was presented at the first National Personality Disorder Congress, Birmingham, 19-20 November 2009. A slideshow presentation delivered at the conference can be accessed at www.personalitydisorder.org.uk/archive/pd-congress-2009 will do the job well is another question. In response to local need and national priorities, a new service was commissioned by the East London NHS Foundation Trust in Tower Hamlets from September 2007. DeanCross Personality Disorder Service forms part of the adult mental health services within the Trust. ${ }^{1}$ It is a dedicated, non-forensic service for people with severe and moderate 
personality disorders. We offer predominantly group-based therapy, with different levels of intensity (including a twomornings-a-week programme for 18 months). The service follows a mentalisation-based treatment approach, ${ }^{2}$ an evidence-based model for borderline personality disorder. ${ }^{3-6}$ In this paper we present our experience of selecting the six clinicians in the team.

\section{UK personality disorder services}

There has been a recent acceleration of development in personality disorder services in the $\mathrm{UK}^{7,8}$ and a recognition of the importance of high-quality staff with the required personal attributes, skills and attitudes. ${ }^{9}$ Key findings of the forthcoming review of the 11 centrally funded community personality disorder services are the importance of the quality of relationships and of staff needing to be selected correctly and supported. ${ }^{10}$

Patients with personality disorder are often disliked by psychiatrists. ${ }^{11}$ The primitive defence mechanisms they tend to use $\mathrm{e}^{12}$ - splitting and projective identification in particular - raise strong anxiety and difficult feelings in the clinician. Given this clinical understanding, and the lack of appropriate psychometric instruments for selecting staff, we based our criteria for staff who can work effectively with patients with a personality disorder on those developed by Bateman \& Fonagy ${ }^{2}$ and the Personality Disorder Capabilities Framework. ${ }^{13}$ We looked for candidates who had the ability to:

- tolerate frustration and anxiety

- maintain boundaries while offering flexibility

- survive hostility without retaliating

- manage internal and external conflict

- be effective team players, working in a multidisciplinary team without insisting on strict, professionally determined demarcation of tasks

- assess threats of suicide without anxiety

- deal with emotional storms with reflection

- maintain a robust but responsive demeanour

- support reflective practice.

We divided our framework for desired staff qualities into three domains, as shown in Table 1.

The recent development of the KUF framework ${ }^{14}$ is welcome, as it recognises the complexity of working with personality disorder. The undergraduate programme aims to 'highlight the interpersonal nature of working with

\begin{tabular}{|c|c|}
\hline $\begin{array}{rr}\text { Table } 1 & \mathrm{Qu} \\
& \text { wit }\end{array}$ & $\begin{array}{l}\text { ities of staff who can work effectively } \\
\text { patients with a personality disorder. }\end{array}$ \\
\hline Domain & Characteristics \\
\hline Psychological & $\begin{array}{l}\text { Robust, flexible thinking, ability to process } \\
\text { information, not too harsh a superego, ability } \\
\text { to reflect on oneself, ability to apply theory } \\
\text { to a practical situation }\end{array}$ \\
\hline Psychiatric & Assessment and management of risk \\
\hline Team & $\begin{array}{l}\text { Team skills, group skills, own identity } \\
\text { balanced with team identity, willingness } \\
\text { to work as a team member }\end{array}$ \\
\hline
\end{tabular}

personality disorder and focus on the personal and professional development of students' (p. 7) and to 'develop an appreciation of the importance of effective teamwork and staff support when working with the challenges of personality disorder' (p. 7). However, personality disorder services will need to recruit staff who will not necessarily have benefited from this training.

\section{Method}

\section{Study preparation}

We reviewed the literature on qualities needed for working with patients with a personality disorder and how these qualities may be assessed in recruitment. Our review focused on the specific question: 'How does one select staff for a psychiatric service or personality disorder service?'. The following databases were searched: MEDLINE, PsycINFO, Embase and CINAHL. The search was restricted to studies published in English between 1995 and 2010. The search terms were: 'personnel selection', 'employee recruitment', 'human resource recruitment', 'psychiatric services and personnel', 'personality disorder services', 'recruitment and assessment', 'interview tasks', 'role play'. Where possible, medical subject headings (MeSH) terms were exploded and combined. In a study on staff recruited to a new dangerous and severe personality disorder unit prepared for the UK Home Office, being more open to new experiences and more prone to negative emotions were related, respectively, to experiencing more enjoyment and a decreased sense of personal security. ${ }^{15}$ However, we found no detailed description of the actual selection process and specifically did not identify studies on how to assess for complex clinical and team-working skills. This is surprising given the clear importance of these aspects, the daily occurrence of staff recruitment, the limitations of curriculum vitae (CV) and stand-alone interviews, and the cost (clinical, managerial and systemic) of selecting the wrong staff. Although literature exists on the use of behavioural assessments, ${ }^{16}$ the sole use of this method provides limited usefulness given the complexity of working with patients who have a personality disorder.

The rationale for the approach we used was essentially to expose applicants to the kind of challenges they could expect in the job. Main themes we selected were: dealing with anxiety, dealing with conflict (both with patients and with colleagues) and risk assessment.

\section{Format}

The interviews lasted a full day and followed the actual sequence of the day:

- a role play with an actor (a fictional life history and script were given to the actor and the role play was piloted before interviews)

- an unstructured group with fellow applicants and members of the interviewing panel (including the service user representative)

- lunch with fellow applicants and staff who were not involved in the selection panel

- a panel interview. 
Role play with an actor

The applicant was supplied with a brief letter from the referrer stating: 'I would like to refer Ms Jones for assessment for treatment by your service. Ms Jones has been followed up by my team for 3 years, although her contact is erratic. She manages for a period in the community but at other times uses our service intensively, when she presents with depressive symptoms and thoughts of self-harm. She has taken numerous overdoses in the past and was admitted under Section 3 [of the Mental Health Act] in 2005. She has carried diagnoses of depression, anxiety disorder and borderline personality disorder. I believe that she is more suited to treatment by a personality disorder service than my team, and would like to discharge her from my service.'

The applicant was instructed to read the letter and then interview the patient for $10 \mathrm{~min}$. They were informed that they would be interviewed by a panel member immediately afterwards and asked to formulate the patient's difficulties and outline a management plan. The objectives of the role play were to assess the ability of the applicant to establish a relationship, gather information effectively, manage a difficult patient, develop a formulation and manage risk.

Unknown to the applicant, the actor was directed to say to the candidate in the third minute: 'I can't concentrate on this interview. I'm worried about my daughter who's going off the rails. Do you have children?'. The actor was also directed to cooperate with the interview for the first $7 \mathrm{~min}$ but then to suddenly switch to being hostile. In the last minute she was instructed to leave the room. As she was about to leave the room she was scripted to say 'I've got tablets at home - you're going to regret having upset me'.

The panel felt we had set an 'impossible task'. Still, the task was retained and it was as much the managing of the task with the patient which was assessed as the attitude of the applicant to him or herself (Did he or she have a harsh superego which constantly criticised him or her for a 'poor' performance?) and to the interviewers the rest of the day.

The role play was done before a panel, who had a marking memorandum to assess the domains as described in Table 1 as well as the candidate's ability to identify important early and later experience, presenting complaints and use of defence mechanisms, and manage the negative transference.

The consultant psychiatrist in the panel then interviewed the candidate, asking to formulate the patient's difficulties using an appropriate model and to outline their management plan. The actor also assessed the applicant on the marking memorandum and discussed her impression of the applicant with the panel immediately after the role play. We conducted a semi-structured interview with the actor regarding her experience of performing the role play for each candidate separately.

Lunch with fellow applicants and the team

Applicants were invited to join the rest of the team for lunch, but they could be on their own if they chose to; the selection panel did not remain with applicants during lunch. The shared lunch was an informal space for the applicants to meet other members of the team and form their own impression of the service, and for the team to make an informal impression of the candidate which was then shared with the panel.

\section{Panel interview}

We were interested in the applicants' thinking process and how they reflected on the day. We aimed to assess whether applicants showed an ability to respond in a dynamic way to the situation rather than provide rehearsed answers, and also how they related to different members of the panel.

\section{Results}

\section{Role play}

The role play allowed an assessment of whether the applicant could actually demonstrate abilities described in the CV. It was especially useful in assessing how applicants managed the negative transference, particularly in response to the defences used by patients with borderline personality disorder, specifically projective identification; in this role play, the projection of the patient's feelings of hopelessness and helplessness to the clinician.

Key aspects of the candidate interview identified by the actor regarded trust, engagement, interviewing style and the applicant's anxiety. Regarding trust, the actor said: 'That was just with my gut - it was just something I felt, just a human-to-human response. It's about trust really'. Regarding engagement, she said: 'I don't want to feel from the person also that I'm just a number, that I'm yet another one that you're doing'. The actor commented on the candidates' interviewing style, for example, 'genuinely open questions' or 'questions felt generic and standardised'. Regarding clinician anxiety, she said for example, 'The candidate felt too anxious, and asked too many leading questions - I would not trust this candidate as my therapist'.

The views of the interviewing staff, service user representative and actor could be compared with one another. This was done predominantly for confirmation but often the disagreements led to a richer discussion and deeper understanding. In one applicant, the interviewing staff had thought they had lacked genuine responses, whereas both the service user representative and actor rated them as trustworthy. In discussion it was clear that the applicant's interpersonal manner had been more concerning to the staff than from the patient's perspective, and staff revised their assessment to score the applicant higher.

\section{An unstructured group with fellow applicants and members of the interviewing panel}

Given the pressure of being in a group with fellow applicants, we could observe whether the applicants could be authentic and reflective regarding the intense feelings generated by the role play, their openness regarding their experience of the role play, their willingness to talk about their anxiety while maintaining appropriate boundaries, whether they showed a sense of humour and what role they took on in the group. 


\section{Panel interview}

One question was a clinical vignette of a dispute between a psychiatrist in the team and the care coordinator, where the psychiatrist wanted to start a patient on an antidepressant immediately and against the existing treatment plan. We assessed whether the applicant was able to maintain a clinical and team perspective or submitted before a medical hierarchy.

\section{Service user representative}

The service user representative added a key perspective, for example by stating during the panel discussion after each role play whether or not they would trust this applicant to be their therapist. During the panel interview the question 'How do you feel having a service user representative on the panel?' discriminated between applicants whose response seemed organised by concerns regarding political correctness and those being able to reflect on the complexity of the process.

\section{Illustration: who to appoint?}

The following case study illustrates how the different methods served to triangulate one another.

\section{Case study}

Applicant 1 had an excellent CV. It was difficult to assess her role play - although she appeared to miss key aspects in the risk assessment, the panel was not certain. When asked to reflect on the role play during the panel discussion, it became clearer that the applicant had successfully covered omissions in her role play. Further, she tried to sit on the fence when discussing the vignette regarding the dispute between the psychiatrist and care coordinator and when asked to commit to a decision gave way before the medical hierarchy. She felt that if that is what the psychiatrist wants she was prepared to go with that. The statement summary regarding the reason to not appoint was: 'A team member at this level needs to be able to deal with conflict with patients and colleagues and to stay with non-resolution and negative situations. This was not demonstrated in several examples'.

Applicant 2 had only a fair $\mathrm{CV}$, far less impressive than applicant 1 . She did a poor risk assessment. During the panel interview she was forthright that she thought she had missed something vital in assessing risk and she was able to think with the panel why this had happened. Crucially, when discussing the clinical vignette, she proved capable of showing resolve and retain the ability to think clinically and in a team context. When faced with the assertive psychiatrist, she held her ground and argued for her clinical point. She was appointed.

\section{The present team}

A focus group of the staff selected from the existing team was conducted by the team's research assistant. Staff felt that the interviewing process did assess the skills required in the job. The following statements reflected a broad view in the group: 'It is harder to get a job on a wing and a prayer in this sort of system. You are very much seen and on show and exposed'; 'It is about being, rather than being able to talk the talk, it is about how you are'. The team selected to date have managed the clinical demands of the job well; they have good job satisfaction, are regarded well by a difficult group of patients, and have a very low sickness rate.

\section{Discussion}

Triangulation (the application of several research methods in studying the same phenomenon) ${ }^{17}$ was extremely useful in the selection process. The methodological triangulation allowed by the use of role play, group participation and panel interview enabled an assessment of the applicant in different settings. Investigator triangulation allowed for multiple observations including the illuminating differences between staff and patient perspectives that at times emerged. Data triangulation involving time and space allowed an assessment of how applicants processed their experience during the course of the day. It enabled the gauging of any countertransference that developed over the day (e.g. some applicants were unable to engage with the consultant psychiatrist in the interview panel as they remained so angry with him following his questions immediately after the role play earlier on in the day). Specifically, regarding the choice between the two applicants presented in the case study, the different way they managed the panel interview helped to discriminate between them, as they had up to that point performed in ways which had left the panel uncertain whom, if either, to appoint. The ability of applicant 2 to be open regarding her limitations and to be clinically confident in defending her viewpoint, made her clearly the preferable appointment for a personality disorder team.

It is difficult to disentangle which assessment method was most discriminatory or helpful, as this differed between applicants. The role play, however, was consistently the most important in establishing an overall impression of the applicant, which could be explored further in the other methods. The presence of a service user representative and actor can prove a vital part of the interview process in representing the patient's perspective.

Adequate time allocation is required for allowing assessment at this depth. This has cost implications as it requires a full working day for three senior professional staff and on average two interviewing days for the appointment of one staff member. The ethical issue of putting applicants through such a gruelling selection process remains, particularly for applicants who were not successful. We remain equivocal about this ourselves. However, faced with the decision of whether to repeat the same approach for ongoing recruitment, we have done so and will continue to do so. In addition, it may be regarded as unethical to appoint someone to a post for which they are incompetent, having not been adequately evaluated.

\section{About the authors}

Tennyson Lee, consultant psychiatrist and psychotherapist, DeanCross Personality Disorder Service, East London NHS Foundation Trust; Claire Ellingford, service user representative, Tower Hamlets User Involvement Project; Samantha Blackburn, research assistant, Elizabeth Bishop, service manager, Nikolas Ragiadakos, deputy service manager, DeanCross Personality Disorder Service; Patricia Elcock, actress, Active Images Company; Kamaldeep Bhui, professor of cultural psychiatry and epidemiology, and honorary consultant, Centre for Psychiatry, Bart's and The London School of Medicine and Dentistry, and Careif. 


\section{References}

1 Garrett C, Lee T, Blackburn S, Priestly L, Bhui K. Personality disorder: challenges in service development in the light of the new NICE guidelines. Psychiatrist 2011; 35: 22-6.

2 Bateman A, Fonagy P. Psychotherapy for Borderline Personality Disorder: Mentalization Based Treatment. Oxford University Press, 2004.

3 Bateman A, Fonagy P. Effectiveness of partial hospitalization in the treatment of borderline personality disorder: a randomized controlled trial. Am J Psychiatry 1999; 156: 1563-9.

4 Bateman A, Fonagy P. Treatment of borderline personality disorder with psychoanalytically orientated partial hospitalisation: an 18 month follow up. Am J Psychiatry 2001; 158: 36-42.

5 Bateman A, Fonagy P. Health service utilisation costs for borderline personality disorder with psychoanalytically orientated partial hospitalisation versus general psychiatric care. Am J Psychiatry 2003; 160: 169-71.

6 Bateman A, Fonagy P. 8-year follow-up of patients treated for borderline personality disorder: mentalisation-based treatment versus treatment as usual. Am J Psychiatry 2008; 165: 631-8.

7 Haigh R. The 16 personality disorder pilot projects. Ment Health Rev J 2007; 12: 29-39.

8 National Institute for Health and Clinical Excellence. Borderline Personality Disorder Treatment and Management (Clinical Guidelines CG78). NICE, 2009.
9 Department of Health. Recognising Complexity: Commissioning Guidance for Personality Disorder Services. Department of Health, 2009.

10 Department of Health. Quality, Innovation, Productivity and Prevention Report on the National Personality Disorder Programme. Department of Health, 2011 (in print)

11 Lewis G, Appleby L. Personality disorder: the patients psychiatrists dislike. Br J Psychiatry 1988; 153: 44-9.

12 Kernberg OF. Borderline personality organisation. J Am Psychoanal Assoc 1967; 15: 641-85.

13 National Institute for Mental Health in England. Breaking the Cycle of Rejection: The Personality Disorder Capabilities Framework. NIMHE, 2003.

14 Institute of Mental Health. Working Effectively with Personality Disorder: The New KUF Framework. IMH, 2009 (http://www. institutemh.org.uk/ images/stories/Personality\%20disorder_nov_09.pdf).

15 Bowers L, Callaghan P, Nijman H, Paton J, Carr-Walker P, Allan T, et al. The Right People for the Job: Choosing Staff that will Adjust Positively and Productively to Working in the New Personality Disorder Services. Report to the Home Office. City University, 2003 (http://www.iop.kcl.ac.uk/ iopweb/blob/downloads/locator/l_436_Rightpeople.pdf).

16 Collins SK. Employee recruitment: using behavioural assessments as an employee selection tool. Health Care Manag 2007; 26: 213-7.

17 Denzin NK. The Research Act in Sociology. Aldine, 1970. 